Julie Ann G. Uy, MD

Jose Carlos Z. Jugo, MD

Jose M. Acuin, MD, MsC

Department of Otorhinolaryngology Head and Neck Surgery

De La Salle Health Sciences Institute De La Salle University Medical Center
Correspondence: Julie Ann G. Uy, MD Department of Otorhinolaryngology Head and Neck Surgery De La Salle University Medical Cente

Pasong Lawin, Dasmarinas, Cavite 4114 Philippines

Phone: (046) 4160226 local 183

Email:july28_md@yahoo.com

Reprints will not be available from the author.

No funding support was received for this study. The authors signed a disclosure that they have no proprietary or financial interest with any organization that may have a direct interest in the subject matter of this manuscript, or in any product used or cited in this report

Presented at the Inter-hospital Grand Rounds, Philippine Society of Otolaryngology - Head and Neck Surgery, University of the East -Ramon Magsaysay Memorial Hospital, September 4, 2007

De La Salle University Center Annual Residents' Research Contest "Case Report Category," (1 ${ }^{\text {st }}$ Place) DLSMC-Dasmarinas Cavite, November 28, 2007

Interesting Case Contest ( $2^{\text {nd }}$ Place) Philippine Society of Otolaryngology - Head and Neck Surgery Midyear Convention, Pryce Plaza Hotel, Cagayan De Oro City, May 2, 2008

\title{
Primary Lymphoma of the Temporal Bone: The First Locally Reported Case
} \begin{abstract}
management in the light of published literature.
\section{Methods:}

Design: Case report

Setting: Private tertiary university hospital

Patient: One
\end{abstract}

ABSTRACT

Objective: To report a case of primary non-Hodgkin's T-cell lymphoma in the temporal bone in a pediatric patient, discussing clinical presentation and course, diagnostic evaluation and

Results: An 8-year-old female with a 10-month history of otalgia and ipsilateral headache developed facial paralysis, unresponsive to topical otic drops and oral antibiotics. Imaging revealed mastoid sclerosis, tegmental and ossicular erosions, and an attico-antral mass which was excised through exploratory tympanomastoidectomy. Final histopath following immunohistochemical corroboration was T-cell lymphoma.

Conclusion: Primary malignant lymphoma of the temporal bone may initially present with otalgia and headache unresponsive to conventional medical management. Ominous signs like facial paralysis should heighten the suspicion of malignancy warranting prompt imaging of the temporal bone. Histopathologic evaluation of all mastoidectomy specimens should be mandatory especially in children, and special stains performed as needed. Patients with $T$ cell $\mathrm{NHL}$ should undergo chemotherapy and may warrant closer follow up for tumor recurrence and disease progression.

\section{Key words: Non-Hodgkin's lymphoma, temporal bone}

Primary malignant lymphoma of the temporal bone has not been reported locally and most internationally documented cases allude to mainly secondary involvement from distant sites. We report the case of an 8-year-old female with a primary T-cell lymphoma of the temporal bone. 


\section{CASE REPORTS}

\section{CASE REPORT}

An eight-year-old girl with a 10-month history of left sided intermittent otalgia and progressively worsening ipsilateral temporal headache developed left sided facial paralysis. Admitted for Bells' Palsy and acute otitis media, her symptoms were unrelieved by topical otic drops and oral antibiotics, and she was eventually referred to our institution for further work-up and management.

She presented with a House-Brackmann 5/6 facial paralysis on the left (Figure 1). A sagging postero-superior external auditory canal wall prevented otoscopic visualization of the tympanic membrane. The rest of the examination was unremarkable, and complete blood count showed leukocytosis with predominance of segmenters.

Initial diagnosis was left facial paralysis secondary to otomastoiditis with cholesteatoma. Computed tomography revealed a well-delineated soft tissue lesion in the left middle ear extending to the external auditory canal and pinna (Figures $2 a, b$ ), sclerosis of mastoid air cells with cortical erosion of the tegmen tympani and ossicular erosion. The left temporal bone appeared thickened and irregular. The right temporal bone was unremarkable. A hyperdense lesion was also seen in the contiguous brain parenchyma, dorsal to the tegmen tympani and anterior to the petromastoid bone (Figure 3), initially read as an abscess but interpreted as cerebritis by a neurosurgeon. Magnetic resonance imaging study was not obtained due to financial constraints.

Exploratory mastoidectomy and facial nerve decompression yielded a fleshy, grayish-white soft tissue mass from the superior and posterior wall of the external auditory canal. The tegmen was granular and the mastoid segment of the facial nerve near the facial ridge was dehiscent. The long process of the malleus, incus, incudostapedial joint, and stapes capitulum were eroded and encased by yellowishwhite soft tissue invading the attic and antrum. The attico-antral and external auditory canal wall soft tissue lesions were excised and a type IVa tympanoplasty was performed.

Partial recovery of facial nerve function to House-Brackmann 3/6 was achieved on the $3^{\text {rd }}$ day post-operative day. A post-operative cranial $\mathrm{CT}$ scan revealed an extra-axial mass lesion anterior and superior to the left temporal bone measuring $2.1 \times 2.1 \mathrm{~cm}$ (Figure $4 a, b$ ).

Histopathologic evaluation of the attico-antral mass revealed only acute suppurative inflammation while the postero-superior canal wall mass showed surface epithelial erosion with fibrosis accompanied by acute and chronic inflammatory cells. Below the epithelium were neoplastic cells seen invading the fibrous stroma (Figure $5 a, b$ ). These cells were generally small, having round, ovoid to irregularlyshaped, hyperchromatic nuclei with fine to coarse chromatin pattern and inconspicuous nucleoli. Cytoplasm was scant and ill-defined; mitosis, rare. This was consistent with a small round cell tumor with the following considerations: lymphoma, peripheral neuroectodermal tumor, neuroblastoma and rhabdomyosarcoma.

Immunohistochemical analysis using CD20 and CD3stains was negative for CD20, ruling out lymphoma of B cell origin, with $60 \%$ of the tumor cells positive for $C D 3$, indicating $T$ cell origin. Additional Terminal Deoxynucleotidyl Transferase or terminal transferase (Tdt) stain was negative, indicating involvement of mature T cells.

Diagnosis was diffuse large cell non-Hodgkin's lymphoma of the Tcell type, and she underwent four courses of induction chemotherapy with vincristine, granisetron, doxorubicin, L-asparaginase, methotrexate, prednisone, G-CSF, and epoietin and recovered facial nerve function to House Brackmann 2/6 (Figure 6). Magnetic resonance imaging revealed marked decrease in size of the left temporal extra-axial mass to $11 \times 6 \mathrm{~mm}$. It was hypodense in all sequences but showed slight inhomogenous enhancement in the contrast phase, and right signals were again seen in the left mastoid air cells indicative of mastoid disease. All other laboratories to identify disease elsewhere were negative.

At the time of this writing, our patient was on her $8^{\text {th }}$ month regular follow up. She had completed the $1^{\text {st }}$ of the 5 courses of consolidation chemotherapy and recovered complete facial nerve function to HouseBrackmann 1/6.

\section{DISCUSSION}

Malignancies of the temporal bone occur rarely, accounting for approximately less than $0.2 \%$ of all head and neck tumors. These include those arising primarily from the skin of the pinna, primary tumors of the external auditory canal, middle ear, mastoid, or petrous apex and metastatic lesions to the temporal bone from distant sites. ${ }^{1}$ The most common malignancy involving the temporal bone is squamous cell carcinoma. Other less common types identified are adenocarcinoma, melanoma, histiocytosis $\mathrm{X}$, rhabdomyosarcoma, osteosarcoma, lymphoma, adenoid cystic carcinoma and acinic cell carcinoma. ${ }^{2}$ The first case of anaplastic carcinoma occurring in the temporal bone was reported locally by Penaflor et al in $1999 .^{3}$

Lymphoid neoplasms account for the majority of non-epithelial malignancies in the head and neck. ${ }^{4}$ An electronic search conducted with the search words "temporal bone" and "lymphoma" revealed only 20 reported cases in international literature." A similar electronic search of the available local database HERDIN collection from 1914 to 2006 revealed no published case report. Inquiries made for unpublished case reports of temporal bone lymphoma in two academic referral hospitals, the Philippine General Hospital and University of Santo Tomas Hospital, found none published locally or reported in scientific conferences.

Primary lymphoma originating in the temporal bone particularly affects the middle ear, mastoid, internal auditory canal and the external auditory canal. Of these sites the middle ear and the mastoid appear to be the most common. ${ }^{6}$

Ogawa et al reviewed 18 case reports of primary lymphoma of the temporal bone ${ }^{t}: 1$ arose from the external auditory canal with no bone destruction, 2 originated from mastoid air cells, and the rest had unidentified sites of origin. Ten patients were elderly adults. The 8 
pediatric cases were all males with an age range of 5 to 16 years old. Five of these 8 patients who underwent immunophenotypic analysis, 1 was of $T$ cell origin and 4 were of $B$ cell origin. ${ }^{7}$ Our patient varied from Ogawa's series in that: (1) she was within the pediatric age group, (2) was female, and (3) had a T cell type of non-Hodgkin's lymphoma.

The initial presentation of progressively worsening unilateral otalgia unresponsive to medical management, temporal headache, and facial paresis with bulging of the postero-superior wall of the external auditory canal prompted the initial impression of chronic middle ear infection, a highly prevalent condition in the Philippines. The facial paresis was then thought to be a complication of a long-standing inadequately treated

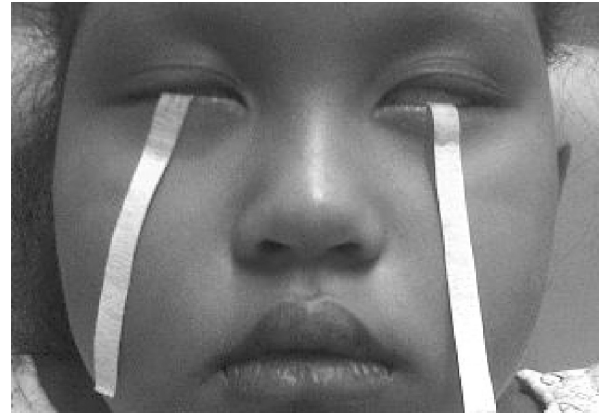

Figure 1. Patient's picture showing incomplete eye closure (during the performance of Schirmer's test) (with permission).

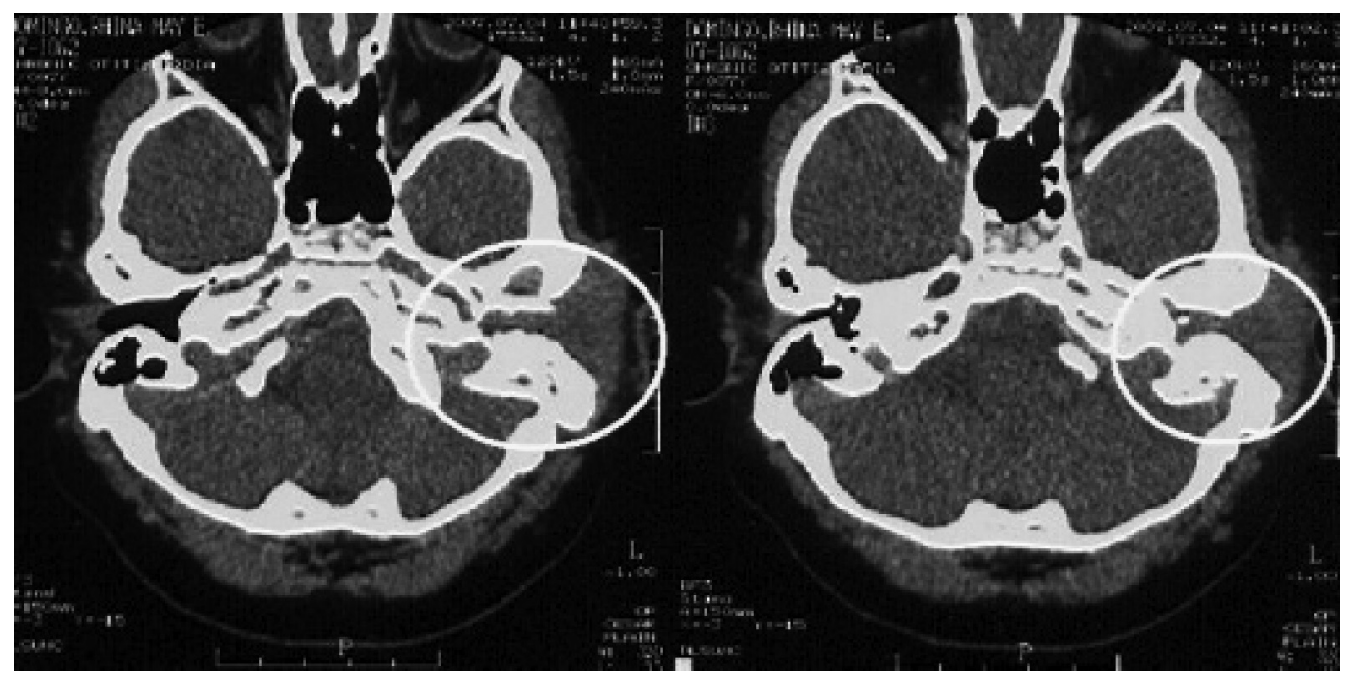

Figure 2. Plain CT scan of the mastoid. $a$ and $b$. Soft tissue density in the left middle ear extending out to the external auditory canal as well as the pinna.

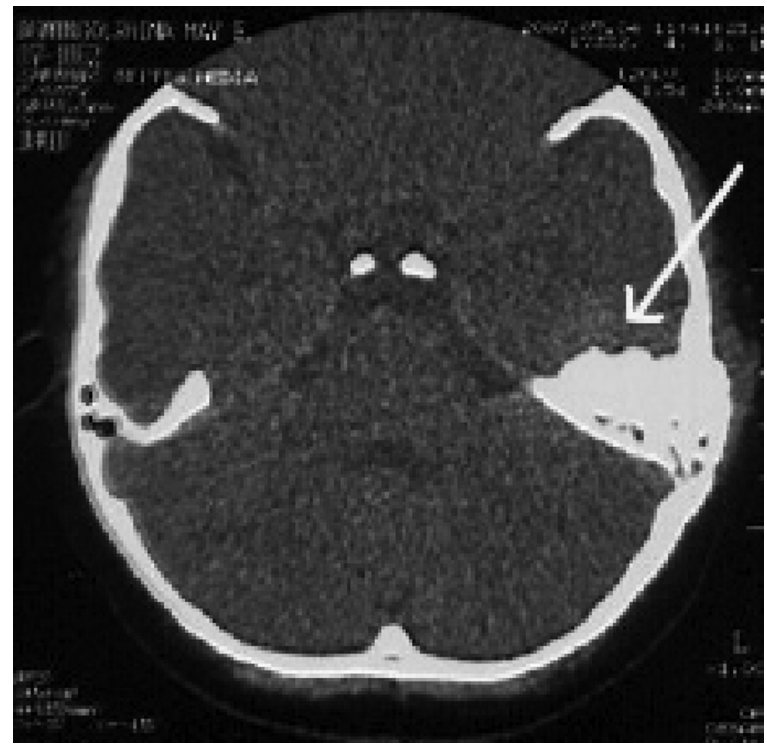

Figure 3. CT scan of the mastoid (Plain). Hyperdense lesion in the contiguous brain parenchyma, dorsal to the tegmen tympani and anterior to the petromastoid bone. 
chronic otomastoiditis. These features were consistent with the initial signs, symptoms, and clinical diagnoses of patients with temporal bone lymphoma. ${ }^{5,7,9}$ Other initial symptoms reported in the literature include decreased hearing, headache, loss of balance, fever and mass in the external auditory canal. ${ }^{7}$

The CT scan findings of this patient are also consistent with other reports. $5,7,9$ Koral et al noted bone erosion and epidural mass in a 15-year-old male with $\mathrm{NHL}^{9}$. Bockmuhl et al found opacification of mastoid air cells on conventional radiographic Schuller's view in a 2year-old male. ${ }^{5}$ Ogawa reported an enhanced mass spreading through both sides of the temporal bone with involvement of the mastoid air cells and the middle ear. MRI of the head was further requested which revealed a destructive mass lesion in the temporal bone. ${ }^{7}$

In the reported case of a primary NHL of the temporal bone in a 2year-old-male with the same clinical presentation as that of the patient, an exploratory mastoidectomy was also performed. This revealed a fleshy soft tissue in the mastoid air cells involving the midvertical portion of the facial nerve. Immunophenotypic analysis revealed a $B$ cell type of $\mathrm{NHL}$ and co-expression of other cell surface molecules like EBV-coded LMP (Latent membrane protein) and CD30 molecule further labeled it as a highly malignant type of lymphoma. Additional staging work-ups were also performed and adjunctive chemotherapy which consisted of 4 cycles of Cyclophosphamide, Adriamycin \& Vincristine was given to the patient. This patient had no tumor recurrence in a 12 month follow-up period and recovery of facial nerve function was also observed after chemotherapy. ${ }^{5}$ On the other hand, both the pediatric patient and adult patients of Tucci only received chemotherapy but also showed recovery of facial nerve function. ${ }^{8}$ (Table 1)

Ogawa's tabulated review of related literature of the 8 pediatric cases of temporal bone lymphoma reported similar therapeutic interventions. A combination of surgery and chemotherapy was given two patients who both survived. Chemotherapy alone was given to four patients where three survived. On the other hand, one of the two patients who did not survive received a combination of chemotherapy and radiotherapy and this patient was the only one with the T cell type of NHL (among the five with immunophenotypic analysis). Surgery was the sole intervention on the one patient who experienced relapse and was lost to follow up. Although the above observations may suggest that chemotherapy with or without surgery is effective therapy for temporal bone lymphoma, findings suggestive of infection and inconclusive for malignancy may justify exploratory mastoidectomy.

Primary malignant lymphoma of the temporal bone may initially present with otalgia and headache unresponsive to conventional medical management. Ominous signs like facial paralysis should heighten the suspicion of malignancy warranting prompt imaging of the temporal bone. Histopathologic evaluation of all mastoidectomy specimens should be mandatory especially in children and special stains performed as needed. Patients with T cell NHL should undergo chemotherapy and may warrant closer follow up for tumor recurrence and disease progression.

\footnotetext{
* 18 cases were included in Ogawa's series and the other 2 cases were from Hersch and Nicolaides

† These cases were collected over 30 years from 1976-2006 from different countries.
}
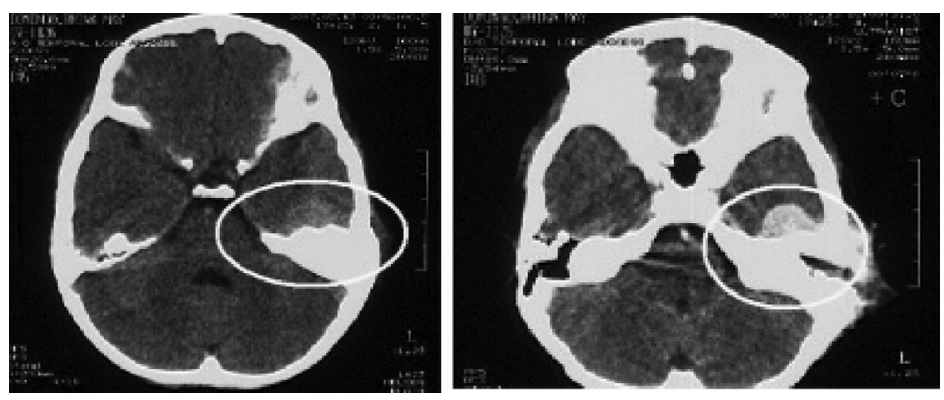

Figure 4. Post-operative CT scan of the mastoid. Homogenously enhancing extra-axial hyperdense lesion anterior and superior to the left temporal bone (a) plain, (b) with contrast
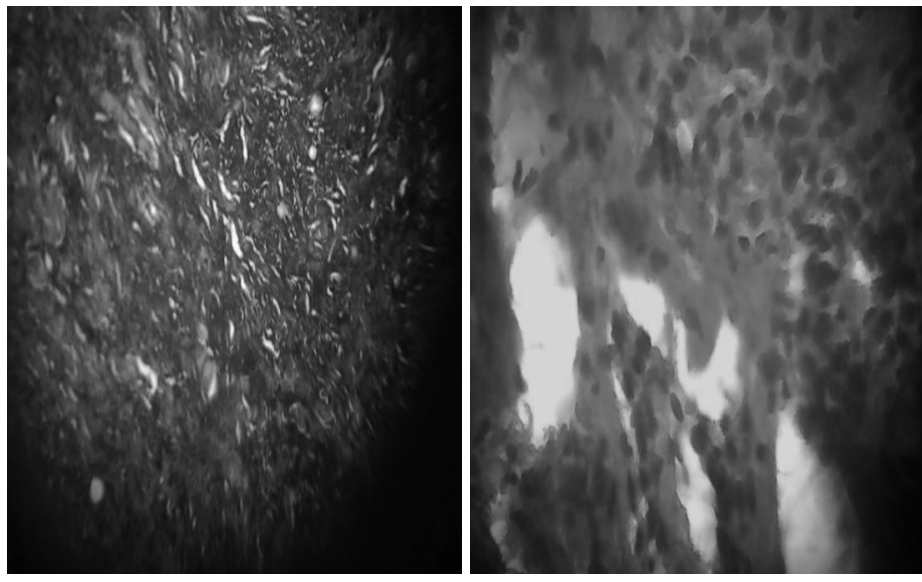

Figure 5. Photomicrograph of the specimen removed from the canal wall revealing a small round cell tumor. (a) low power view, and (b) high power view

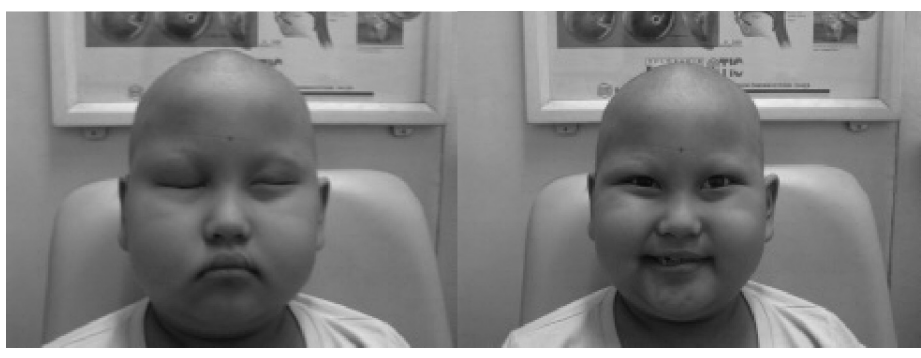

Figure 6. Patient's picture. Recovery of facial nerve function graded as House-Brackmann 2/6 on the left side (with permission). 
CASE REPORTS

Table 1. Summary of the Therapeutic Intervention and Outcome of Primary Temporal Bone Lymphoma Cases

\begin{tabular}{|c|c|c|c|c|}
\hline Author & Age/Gener & Immunophenotype & Therapy & Outcome \\
\hline $\begin{array}{l}\text { Blockmuhl } \\
\text { (1995) }\end{array}$ & $2 / \mathrm{M}$ & B cell & $\begin{array}{l}\text { Mastoidectomy \& Ad- } \\
\text { junctive Chemotherapy }\end{array}$ & $\begin{array}{l}\text { - Recovery of facial nerve } \\
\text { function } \\
\text { - Disease free (12 month } \\
\text { follow up) }\end{array}$ \\
\hline \multirow[t]{2}{*}{ Tucci (1992) } & $5 / M$ & $(-)$ & Chemotherapy & $\begin{array}{l}\text { - Recovery of facial nerve } \\
\text { function }\end{array}$ \\
\hline & $66 / M$ & $(-)$ & Chemotherapy & $\begin{array}{l}\text { - Recovery of facial nerve } \\
\text { function }\end{array}$ \\
\hline
\end{tabular}

\section{APPENDIXA}

\section{House - Brackmann Grading System ${ }^{10}$}

\begin{tabular}{|c|c|}
\hline Grade & Characteristics \\
\hline I. Normal & Normal facial function in all areas \\
\hline $\begin{array}{l}\text { II.Mild } \\
\text { Dysfunction }\end{array}$ & $\begin{array}{l}\text { Gross } \\
\text { - Slight weakness noticeable on close inspection } \\
\text { - May have slight synkinesis } \\
\text { - At rest, normal symmetry and tone } \\
\text { Motion } \\
\text { - Forehead - Moderate-to-good function } \\
\text { - Eye - Complete closure with minimal effort } \\
\text { - Mouth - Slight asymmetry }\end{array}$ \\
\hline $\begin{array}{l}\text { III. Moderate } \\
\text { Dysfunction }\end{array}$ & $\begin{array}{l}\text { Gross } \\
\text { - Obvious but not disfiguring difference between } \\
\text { the two sides } \\
\text { - Noticeable but not severe synkinesis, contracture, } \\
\text { or hemifacial spasm } \\
\text { - At rest, normal symmetry and tone } \\
\text { Motion } \\
\text { - Forehead - Slight-to-moderate movement } \\
\text { - Eye - Complete closure with effort } \\
\text { - Mouth - Slightly weak with maximum effort }\end{array}$ \\
\hline $\begin{array}{l}\text { IV. Moderately } \\
\text { Severe } \\
\text { Dysfunction }\end{array}$ & $\begin{array}{l}\text { Gross } \\
\text {. Obvious weakness and/or disfiguring asymmetry } \\
\text {-At rest, normal symmetry and tone } \\
\text { Motion } \\
\text { - Forehead - None } \\
\text { - Eye - Incomplete closure } \\
\text { - Mouth - Asymmetric with maximum effort }\end{array}$ \\
\hline $\begin{array}{l}\text { V.Severe } \\
\text { Dysfunction }\end{array}$ & $\begin{array}{l}\text { Gross } \\
\text { - Only barely perceptible motion } \\
\text {-At rest, asymmetry } \\
\text { Motion } \\
\text { - Forehead - None } \\
\text { - Eye - Incomplete closure } \\
\text { - Mouth - Slight movement }\end{array}$ \\
\hline $\begin{array}{l}\text { VI.Total } \\
\text { Paralysis }\end{array}$ & No movement \\
\hline
\end{tabular}

\section{ACKNOWLEDGEMENTS}

We would like to express our heartfelt appreciation to the consultant staff of the DLSUMC Department of ENT for their ideas and contributions during the preparation of this paper.

\section{REFERENCES}

1. Lim LH, Goh YH, Chan YM. Malignancy of the temporal bone and external auditory canal. Otolaryngol Head Neck Surg. 2000 Jun;122(6):882-6.

2. Zhang $B, T u ~ G, X u$ G. Squamous cell carcinoma of temporal bone: reported on 33 patients. Otolaryngol Head Neck Surg. 1999 Aug; 21(5):461-6.

3. Penaflor N, Jugo JCZ, Abes GT. Anaplastic cancer of the temporal bone presenting as chronic otitis media. Philipp J Otolaryngol Head Neck Surg. 1999;14(4): 26-32.

4. Paparella MM,el-Ficky FM. Ear involvement in malignant lymphoma. Ann Otol Rhinol Laryngol. 1972;81:356-63.

5. Bockmuhl U, et al. Primary non-Hodgkin's lymphoma of the temporal bone. Eur Arch Otorhinolaryngol. 1995; 252:376-378.

6. Hersh D. Primary B cell lymphoma of the external auditory canal. Ear, Nose, Throat J. 2006 Sept: 85(9):597-9.

7. Shoko Ogawa, Isao Tawara, Satoshi Ueno, Miho Kimura, Kana Miyazaki, Hiroyoshi Nishikawa, et al. De novo CD5-positive diffuse large B-cell lymphoma of the temporal bone presenting with an external auditory canal tumor. Intern. Med. 2006; 45:733-737.

8. Tucci DL, Lambert PR, Innes DJ Jr. Primary lymphoma of the temporal bone. Auris Nasus Larynx. 1992; 19(1):28-35

9. Koral K, Curran JG, Thompson A. Primary non-Hodgkin's lymphoma of the temporal bone: CT findings. Auris Nasus Larynx; 1994; 21(1): 1-7.

10. House JW, Brackmann DE. Facial nerve grading system. Otolaryngol Head Neck Surg. 1985; 93:146. 